\title{
A Case Report of Successful Kidney Donation After Brain Death Following Nicotine Intoxication
}

Rasanen, M.

2017

Rasanen , M , Helanterä , I , Kalliomaki , J , Savikko , J , Parry , M \& Lempinen , M 2017 , ' A

Case Report of Successful Kidney Donation After Brain Death Following Nicotine

Intoxication ' , Transplantation Proceedings , vol. 49 , no. 1 , pp. 229-231 . https://doi.org/10.1016/j.transproceed.201

http://hdl.handle.net/10138/236406

https://doi.org/10.1016/j.transproceed.2016.08.043

publishedVersion

Downloaded from Helda, University of Helsinki institutional repository.

This is an electronic reprint of the original article.

This reprint may differ from the original in pagination and typographic detail.

Please cite the original version. 


\title{
A Case Report of Successful Kidney Donation After Brain Death Following Nicotine Intoxication
}

\author{
M. Räsänen ${ }^{a, *}$, I. Helanterä ${ }^{a}$, J. Kalliomäki ${ }^{b}$, J. Savikko ${ }^{a}$, M. Parry ${ }^{c}$, and M. Lempinen ${ }^{a}$

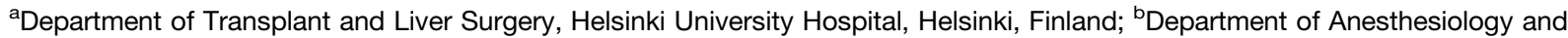 \\ Intensive Care Unit, Tampere University Hospital, Tampere, Finland; and ${ }^{\mathrm{C} P o i s o n}$ Information Centre, Department of Emergency \\ Medicine, Helsinki University Hospital, Helsinki, Finland
}

\begin{abstract}
Nicotine intoxication is a rare cause of death and can lead to brain death after respiratory arrest and hypoxic-ischemic encephalopathy. To our knowledge, no previous reports regarding organ donation after nicotine intoxication have been described. We present a successful case of kidney donation after brain death caused by subcutaneous nicotine overdose from liquid nicotine from an e-cigarette cartridge in an attempted suicide. Both kidneys were transplanted successfully with immediate graft function, and both recipients were discharged at postoperative day 9 with normal plasma creatinine levels. Graft function has remained excellent in follow-up. This case suggests that kidneys from a donor with fatal nicotine intoxication may be successfully used for kidney transplantation in the absence of other contraindications for donation.
\end{abstract}

$\mathbf{N}^{\prime}$ ICOTINE IS HIGHLY TOXIC AND very addictive. Although nicotine intoxication is a rare cause of death, several cases have been reported, and instructions for abuse of nicotine for suicidal purposes are readily available on the Internet. Fatal nicotine intoxications have been reported after use of transdermal nicotine patches [1], subcutaneous routes, and highly concentrated nicotine extract drinks [2,3].

Today's smokeless tobacco, mainly in the form of electronic nicotine delivery systems (also known as electronic cigarettes or e-cigarettes), is becoming increasingly popular. E-cigarettes originally contain 0 to $20 \mathrm{mg}$ of nicotine; the refill kits, however, have been found to have even higher nicotine contents than the original cartridges, up to $72 \mathrm{mg} / \mathrm{mL}$ [4]. Furthermore, discrepancies of up to $89 \%$ between the label and the actual nicotine content have been reported [5]. Thus, one $50-\mathrm{mL}$ vial can contain a fatal amount of nicotine for 50 adults [2]. In addition, $>2000$ various chemicals compounds have been identified in current e-cigarette liquids, some of them harmful. These include ultraparticles and volatile organic compounds, such as metals and silicate particles [6,7]. Sales of such kits are poorly regulated, and they are readily available over the Internet, enabling their use also for suicidal purposes.

Nicotine poisoning can be confirmed by measuring plasma nicotine levels [8]. Because nicotine has no antidote, treatment is symptomatic. In the case of oral exposure, activated charcoal can be given to prevent uptake [9].

We present a successful case of kidney donation after brain death due to subcutaneous nicotine overdose. To our knowledge, this case is the first of organ donation after nicotine-induced brain death.

\section{CASE REPORT}

The patient was a 29-year-old female with a history of severe depression and morbid obesity (height, $170 \mathrm{~cm}$; weight, $150 \mathrm{~kg}$; and body mass index, $52 \mathrm{~kg} / \mathrm{m}^{2}$ ). Her current medication consisted only of diazepam.

After consuming $75 \mathrm{mg}$ of diazepam accompanied by some doses of alcoholic beverages, the patient subcutaneously injected $10 \mathrm{~mL}$ of liquid nicotine from an e-cigarette cartridge in an attempted suicide. The amount of injected nicotine from the cartridge was estimated between 100 and $400 \mathrm{mg}$. After calling an ambulance herself at 2:56 AM, she was taken to the local university hospital. The patient presented with anxiety and hyperventilation but was hemodynamically stable. Her blood ethanol content was estimated

*Address correspondence to Minna Räsänen, MD, Department of Transplant and Liver Surgery, Helsinki University Hospital, Haartmaninkatu 4, PI 340, 00029 Helsinki, HUS, Finland. E-mail: minna.rasanen@hus.fi

$0041-1345 / 16$ http://dx.doi.org/10.1016/j.transproceed.2016.08.043 
at $0.16 \mathrm{mg} / \mathrm{L}$ based on measurement of exhaled ethanol. The patient was given an oral dose of oxazepam $30 \mathrm{mg}$ to relieve anxiety. After a sudden convulsion, regurgitation, and aspiration, respiratory and cardiac arrest followed 2.5 hours after presentation. She was successfully resuscitated from asystole, with return of spontaneous circulation after 14 minutes. She was intubated and admitted to the intensive care unit (ICU).

In the ICU, the patient was hemodynamically unstable and received norepinephrine as a continuous infusion. Her electrolyte balance remained stable, and diuresis was ongoing with hydration. Because of aspiration, she was started on intravenous cefuroxime ( $1.5 \mathrm{~g}$ every 6 hours), and levetiracetam ( $2 \mathrm{~g}$ followed by $1 \mathrm{~g}$ twice daily) was initiated because of tremor. In follow-up at the ICU, she was unresponsive with a constant Glasgow Coma Scale of 3 without sedation. Brain death was confirmed by lack of spontaneous ventilation and computed tomographic angiography showing no cerebral blood flow on the following day of hospital admission. The cause of death was hypoxic-ischemic encephalopathy caused by lethal nicotine intoxication.

Transplantation coordinators were contacted after brain death was confirmed. Results of the patient's laboratory tests were unremarkable for plasma creatinine $(106-70 \mu \mathrm{mol} / \mathrm{L})$ and electrolyte balance (potassium, $3.4 \mathrm{mmol} / \mathrm{L}$; sodium, $145 \mathrm{mmol} / \mathrm{L}$ ), whereas transaminase activities were moderately elevated (alanine aminotransferase, $534 \mathrm{IU} / \mathrm{L}$; gamma-glutamyl transferase, $140 \mathrm{IU} / \mathrm{L}$ ), and she was accepted as a kidney donor. Due to impaired left ventricular function, the heart could not be accepted for transplantation, and the liver was discarded due to extensive steatosis. The organ retrieval operation was uneventful. The kidneys were perfused with University of Wisconsin solution.

Suitable HLA-matched crossmatch-negative kidney recipients were selected from the same blood group $(\mathrm{O})$. The first recipient was a 39-year-old woman, with a medical history of type 1 diabetes and diabetic nephropathy as the cause of end-stage renal disease, with maintenance dialysis initiated 10 months earlier. Other comorbidities included hypercholesterolemia, hypertension, and glaucoma. HLA-AB/DR mismatch was $2 / 0$, and her baseline immunosuppressive regimen was a combination of cyclosporine, methylprednisolone, and mycophenolate. The right kidney of the donor was transplanted to the right side of the recipient with a cold ischemia time of 19 hours and 9 minutes. The anatomy of the kidney was normal. Graft function started on the first postoperative day, and no postoperative dialysis was needed. Recovery from the operation was uneventful, and the patient was discharged on postoperative day 9 with a plasma creatinine level of $59 \mu \mathrm{mol} / \mathrm{l}$. At discharge, her immunosuppressive regimen consisted of cyclosporine $125 \mathrm{mg}+100$ $\mathrm{mg}$, mycophenolate $1 \mathrm{~g}$ twice daily, and methylprednisolone $16 \mathrm{mg}$ once daily. Ten months after transplantation, the patient is doing well, with a plasma creatinine level of $54 \mu \mathrm{mol} / \mathrm{L}$.
The second recipient was a 43-year-old woman, who similarly had type 1 diabetes and diabetic nephropathy as the cause of end-stage renal disease, with maintenance dialysis treatment initiated 36 months earlier. HLA-AB/DR mismatch was $1 / 1$. Pretransplant panel reactive antibodies were $65 \%$ in class I and $17 \%$ in class II. The woman received induction with basiliximab, and maintenance immunosuppressive therapy included a combination of tacrolimus, methylprednisolone, and mycophenolate. The left kidney with normal anatomy was transplanted to the left side. The cold ischemia time was 23 hours and 50 minutes. Graft function started on the first postoperative day, and no postoperative dialysis was needed. Recovery from the operation was uneventful, and the patient was discharged on postoperative day 9 with a plasma creatinine level of $75 \mu \mathrm{mol} / \mathrm{L}$. At discharge, the immunosuppressive regimen consisted of tacrolimus $5 \mathrm{mg}$ twice daily, mycophenolate $500 \mathrm{mg}$ twice daily, and methylprednisolone $16 \mathrm{mg}$ once daily. Ten months after transplantation, the patient is doing well, and her plasma creatinine level is $59 \mu \mathrm{mol} / \mathrm{l}$.

\section{DISCUSSION}

E-cigarettes were first commercialized in China $\sim 10$ years ago, and the market for these products has been rapidly expanding [7]. Their popularity is based on the assumption that e-cigarettes may be less harmful than conventional cigarettes because no tobacco is burned [6]. In conventional cigarettes, the nicotine content varies between 10 and $30 \mathrm{mg}$ per cigarette, and the absorbed nicotine from 1 cigarette is estimated at 0.05 to $3 \mathrm{mg}[9,10]$. The mean lethal dose of nicotine in adults has been estimated to be between 30 and $60 \mathrm{mg}(0.5-1.0 \mathrm{mg} / \mathrm{kg})$ and $\sim 10 \mathrm{mg}$ in children [8]. There is great variability of uptake between the different routes of administration. Nicotine is poorly absorbed from the acidic environment of the gastrointestinal tract, whereas inhalation or absorption from mucous membranes is better. In the present case, 100 to $400 \mathrm{mg}$ of nicotine was injected subcutaneously, effectively increasing bioavailability. Our patient developed many symptoms compatible with nicotine intoxication (Table 1) and was treated symptomatically.

Nicotine is a water- and lipid-soluble liquid alkaloid. The half-life of nicotine is 1 to 4 hours, with up to $90 \%$ of nicotine metabolized mainly to cotinine via cytochrome oxidase routes in the liver [8]. Nicotine and its metabolites are excreted in urine. Nicotine targets the nicotinic acetylcholine receptors in the peripheral and central nervous systems, mimicking the effects of acetylcholine. The effects

Table 1. Summary of the Toxic Symptoms Produced by Nicotine Overdose

\begin{tabular}{|c|c|c|}
\hline \multirow[b]{2}{*}{ Organ System } & \multicolumn{2}{|l|}{ Symptom } \\
\hline & Initial & Late \\
\hline Gastrointestinal & Nausea, vomiting, salivation, abdominal pain, and diarrhea & \\
\hline Cardiovascular & Hypertension, tachyarrhythmias, and peripheral vasoconstriction & Bradycardia, cardiac arrest \\
\hline Respiratory & Tachypnea & $\begin{array}{c}\text { Dyspnea, decreased respiratory rate, } \\
\text { respiratory arrest }\end{array}$ \\
\hline Central nervous system & Confusion, agitation & $\begin{array}{c}\text { Dizziness, convulsions, coma, central } \\
\text { respiratory arrest }\end{array}$ \\
\hline
\end{tabular}

Initial symptoms are due to stimulation of nicotinic acetylcholine receptors; late symptoms are due to inhibition of the receptors. Text given in boldface indicates the symptoms observed in our patient. 
of nicotine are initially due to stimulation of nicotinic acetylcholine receptors, whereas large doses cause depressive effects via substrate inhibition (Table 1) [9]. The initial symptoms of nicotine toxicity can present in up to 15 minutes. Death is usually rapid, within 1 hour of exposure, usually after respiratory depression; arrhythmias are possible, however [8]. Brain death usually follows hypoxicischemic encephalopathy.

Because of the large amount of nicotine metabolized by the liver in the present case, the liver was not considered acceptable for transplantation. In addition, extensive steatosis was diagnosed, supporting the decision to discard the liver. The effect of nicotine poisoning to the kidneys was discussed with the Finnish poison information center. Even though up to 8 times higher nicotine concentrations have been reported in the kidneys compared with serum concentrations [2], no reports of nephrotoxicity after nicotine overdose or even long-term exposure were found. Because no damage was evident at the time of donation and the elimination half-life of nicotine is low, the donor kidneys were accepted for transplantation. In this case, the transplanted kidneys started to function immediately on the first postoperative day without need for postoperative dialysis. Ten months later, kidney function remains stable in both recipients, and plasma creatinine levels have shown excellent function of the grafts.

\section{CONCLUSIONS}

Our present case suggests that kidneys from a donor with fatal nicotine intoxication may be successfully used for kidney transplantation in the absence of other contraindications for donation.

\section{ACKNOWLEDGMENTS}

The authors thank the co-operating hospital.

\section{REFERENCES}

[1] Lardi C, Vogt S, Pollak S, Thierauf A. Complex suicide with homemade nicotine patches. Forensic Sci Int 2014;236:e14-8.

[2] Bartschat S, Mercer-Chalmers-Bender K, Beike J, Rothschild MA, Jubner M. Not only smoking is deadly: fatal ingestion of e-juice-a case report. Int J Legal Med 2015;129: $481-6$.

[3] Schneider S, Diederich N, Appenzeller B, Schartz A, Lorang $\mathrm{C}$, Wennig $\mathrm{R}$. Internet suicide guidelines: report of a life-threatening poisoning using tobacco extract. J Emerg Med 2010;38:610-3.

[4] Cobb NK, Abrams DB. E-cigarette or drug-delivery device? Regulating novel nicotine products. N Engl J Med 2011;365:193-5.

[5] Goniewicz ML, Kuma T, Gawron M, Knysak J, Kosmider L. Nicotine levels in electronic cigarettes. Nicotine Tob Res 2013;15: 158-66.

[6] Williams M, Villarreal A, Bozhilov K, Lin S, Talbot P. Metal and silicate particles including nanoparticles are present in electronic cigarette cartomizer fluid and aerosol. PLoS One 2013;8: e57987.

[7] Lippi G, Favaloro EJ, Meschi T, Mattiuzzi C, Borghi L, Cervellin G. E-cigarettes and cardiovascular risk: beyond science and mysticism. Semin Thromb Hemost 2014;40:60-5.

[8] Higa de Landoni J. Nicotine. International Programme on Chemical Safety. <http://www.inchem.org/documents/pims/chemical/ nicotine.htm/>; 1991. [Accessed December 20, 2016].

[9] Soghoian S. Nicotine. In: Hoffman RS, Howland MA, Lewin NA, Nelson LS, Goldfrank LR, editors. Goldfrank's toxicologic emergencies. 10th ed. New York: McGraw-Hill Education; 2015. p. 1138-43.

[10] Federal Trade Commission. Report on tar, nicotine, and carbon monoxide, covering 1998. Washington, DC: Federal Trade Commission. <www.ftc.gov/reports/2000- report-tarnicotine- carbonmonoxide-covering-1998/>; 2000. [Accessed December 20, 2016]. 